\title{
Effects of ambient temperatures on evolutionary potential of reproductive timing in boreal passerines
}

\section{Vatka, Emma}

2021-02

Vatka , E , Orell , M , Rytkönen , S \& Merilä , J 2021 , ' Effects of ambient temperatures on evolutionary potential of reproductive timing in boreal passerines ' , Journal of Animal Ecology , vol. 90 , no. 2 , pp. 367-375 . https://doi.org/10.1111/1365-2656.13370

http://hdl.handle.net/10138/335333

https://doi.org/10.1111/1365-2656.13370

unspecified

acceptedVersion

Downloaded from Helda, University of Helsinki institutional repository.

This is an electronic reprint of the original article.

This reprint may differ from the original in pagination and typographic detail.

Please cite the original version. 
1 Effects of ambient temperatures on evolutionary potential of reproductive timing in boreal

2 passerines

3

4 Emma Vatka ${ }^{1^{*}}$, Markku Orell ${ }^{2}$, Seppo Rytkönen ${ }^{2}$, Juha Merilä ${ }^{1}$

5

$6 \quad{ }^{1}$ Ecological Genetics Research Unit, Organismal and Evolutionary Biology Research Programme,

7 Faculty Biological \& Environmental Sciences, University of Helsinki, P. O. Box 65, FI-00014

8 University of Helsinki, Finland

$9 \quad{ }^{2}$ Ecology and Genetics Research Unit, Faculty of Science, University of Oulu, P.O. Box 3000, FI-

1090014 University of Oulu, Finland

11

12 *Corresponding author: Emma Vatka, e-mail:emma.vatka@helsinki.fi, ORCID ID: orcid.org/0000-

$13 \quad 0003-2935-8295$

14 


\section{Abstract}

1. Many populations need to adapt to changing environmental conditions, such as warming climate. Changing conditions generate directional selection for traits critical for fitness. For evolutionary responses to occur, these traits need to be heritable. However, changes in environmental conditions can alter the amount of heritable variation a population expresses, making predictions about expected responses difficult.

2. The aim of this study was to evaluate the effects of ambient temperatures on evolutionary potential and strength of natural selection on the timing of reproduction in two passerine birds breeding in boreal forests.

3. Long-term data on individually marked Willow Tits (Poecile montanus, 1975-2018) and Great Tits (Parus major, 1969-2018) were analysed with random regression animal models to assess if spring temperatures affect the expressed amount of additive genetic variation $\left(V_{A}\right)$ and heritability $\left(h^{2}\right)$ in the timing of breeding. We assessed if ambient temperatures of different seasons influenced the direction and strength of selection on breeding time. We also evaluated if the strength of selection co-varied with evolutionary potential.

4. Levels of $V_{A}$ or $h^{2}$ expressed in laying date were unaffected by spring temperatures in both study species. Selection for earlier breeding was found in the Willow Tit, but not in the Great Tit. In the Willow Tit, selection for earlier breeding was more intense when the temperatures of following autumns and winters were low. Different measures of evolutionary potential did not co-vary strongly with the strength of selection in either species.

5. We conclude that there is no or little evidence that climate warming would either constrain or promote evolutionary potential in timing of breeding through changes in amount of genetic variance expressed in boreal Willow and Great Tits. However, selection on the timing of breeding, a life-history event taking place in springtime, is regulated by 

reduce the rate of expected evolutionary response in reproductive timing.

42

43

44 Keywords: breeding time, climate change, heritability, natural selection, quantitative genetics 45 
Many populations are facing a need to adapt to changing environmental conditions, such as to those brought along by the ongoing anthropogenically driven climate change. An evolutionary response is possible, if a trait is subject to directional natural selection, and there is heritable variation in the

51 trait in question (Lynch \& Walsh, 1998). However, changes in environmental conditions not only influence the strength of selection, but they can also affect traits' evolutionary potential through changing the amount of heritable variation a population expresses (e.g. Wilson et al., 2006).

The amount of genetic variation a population expresses in given trait is not constant, but it may vary according to environmental conditions that prevail (Hoffmann \& Merilä, 1999). Phenotypic plasticity refers to genotype's ability to produce different phenotypes in different environmental conditions (Pigliucci, 2001), and inter-individual variation in the amount of phenotypic plasticity can make population to express different amounts of genetic variation in different environmental conditions. Unfavourable conditions may either decrease or increase the amount of genetic variation a population expresses (Hoffmann \& Merilä, 1999). For example, poor nutrition often results in lowered heritability of body size in birds (Gebhardt-Henrich \& van Noordwijk, 1991; Hoffmann \& Merilä, 1999, Merilä \& Sheldon, 2000). It is also possible that harsh conditions lead to increased heritability, as often has been observed in insect studies (Hoffmann \& Merilä, 1999).

The narrow-sense heritability $\left(h^{2}\right)$ of a trait is defined as the proportion of the phenotypic variance $\left(V_{P}\right)$ ascribable to additive genetic variance $\left(V_{A}\right)\left(h^{2}=V_{A} / V_{P}\right)$. It indicates the extent to which a trait can be expected to evolve in response to directional selection. However, variation in heritability can be induced either by changes in additive genetic or residual variance (e.g. Merilä \& Sheldon, 1999, Wheelwright et al., 2014). Thus, heritability may not be a practical measure to compare evolutionary potential between traits or between populations. Hansen, Pélabon, and Houle (2011) suggest that heritability is not a suitable stand-alone measure of evolutionary potential in the 
wild, especially when comparing populations or species. However, comparisons of heritabilities of the same trait in different environmental conditions are valid.

73 Changes in the amount of expressed heritable variation may or may not be coupled with the same environmental factors that determine the strength of natural selection. Heritability values can correlate with the strength of natural selection (Merilä, 1997, Wilson et al., 2006), but this is not a universal phenomenon (Ramakers, Culina, Visser, \& Gienapp, 2018a). Climate warming has affected phenologies of different organisms in both terrestrial and aquatic environments (e.g. Walther et al., 2002, Parmesan \& Yohe, 2003, Root et al., 2003). Different rates of phenological shifts among interacting species can lead to temporal mismatches between e.g. a predator and its prey (Visser \& Both, 2005), which can give rise to novel selection pressures. In the temperate zone

81 Dutch Great Tit (Parus major) population, availability of caterpillar food during the nestling period that affects natural selection on breeding time is linked with spring temperature (Ramakers, Gienapp, \& Visser, 2018b). However, in the boreal zone, the strength of natural selection may be more strongly affected by winter than spring temperatures. For instance, unfavourable spring conditions do not necessarily result in high mortality rates in the following winter if winter conditions are favourable. In fact, winter temperatures in Northern Europe are rising more rapidly than temperatures during other seasons (Ruosteenoja, Jylhä, \& Kämäräinen, 2016).

The aim of this study was to evaluate the effects of ambient temperatures on evolutionary potential and strength of natural selection on the timing of breeding in two passerine birds breeding in boreal zone forests. We analysed long-term data on individually marked and pedigreed Willow Tit (Poecile montanus, 1975-2018) and Great Tit (1969-2018) populations to address the following two questions: First, do spring temperatures affect the expressed amount of additive genetic variation $\left(V_{A}\right)$ and heritability $\left(h^{2}\right)$ in breeding time in two species? Second, how do ambient temperatures of different seasons affect the direction and strength of selection on breeding time, and 
95 does the strength of selection co-vary with levels of expressed additive genetic variance and 96 heritability? 


\section{$\underline{\text { Study species }}$}

100 Willow Tits and Great Tits are small hole-nesting passerine birds. The Willow Tit is a boreal forest 101 specialist with a declining population size (Hyvärinen, Juslén, Kemppainen, Uddström, \& Liukko, 2019), whereas the Great Tit has relatively recently expanded its range to the boreal zone and the population size is growing (Valkama, Vepsäläinen, \& Lehikoinen, 2011). Willow Tits breed in cavities they have excavated in decaying stumps, whereas Great Tits accept nest boxes. The timing of breeding is affected by spring temperatures both in the Willow Tit (Vatka, Orell, \& Rytkönen, 2011) and in the Great Tit (Vatka, Rytkönen, \& Orell, 2014) - both populations show advancing long-term trends in reproductive timing. Annual median egg-laying dates of Willow Tits are strongly correlated with the mean ambient temperature of the period March 27-May $6\left(\mathrm{R}^{2}=0.717\right.$; Vatka et al., 2011). For the Great Tit, the corresponding period is 29 March-15 May $\left(\mathrm{R}^{2}=0.721\right.$; Vatka et al., 2014). Spring temperatures also determine the timing of the main food source for 111 nestling provisioning: caterpillars of moths and sawflies that forage in tree canopies (Vatka et al., 112 2011, 2014). Warming of springs has not yet led to a temporal mismatch between the caterpillar 113 availability and nestlings' food demands in the study populations - in fact, the match with the food 114 peak has improved in the Willow Tit (Vatka et al., 2011, 2014).

Willow Tits spend their winters in territorial flocks whose social hierarchy is influenced by prior 117 residency (Koivula, Lahti, Orell, \& Rytkönen, 1993). Willow Tits hoard food for winter (Brodin, 118 Lahti, Lens \& Suhonen, 1996) and young from early broods have more time to prepare for the 119 upcoming winter. Because of these, Willow Tit young from relatively early broods have higher 120 recruitment rates than young from late broods, whereas for the Great Tit, recruitment rates are better 121 explained by synchrony with the caterpillar food availability (Pakanen, Orell, Vatka, Rytkönen, \& 
Broggi, 2016). Winter survival of boreal Great Tits depends primarily on food supplied by humans

123 (Orell, 1989).

$\underline{\text { Study area }}$

126 The Oulu study area in Northern Finland (ca. $65^{\circ} 05^{\prime} \mathrm{N}, 25^{\circ} 33^{\prime} \mathrm{E}$ ) consists of coniferous, deciduous 127 and mixed forests and swamps of varying ages (Orell \& Ojanen, 1983a, b; Rytkönen \& Orell, 128 2001). Similar forest habitats continue outside the study area, and thus the study populations are 129 open. The Willow Tit study area has expanded in size, starting from ca. $2 \mathrm{~km}^{2}$ in 1975 (Orell \& 130 Ojanen, 1983c) and gradually increasing to ca. $25 \mathrm{~km}^{2}$ in 1996 . From 1969 onwards, 100-400 131 wooden nest boxes were provided for Great Tits in separate sub-areas of $2-4 \mathrm{~km}^{2}$ total in $1969-$ 132 1997, and since 1998, in four neighbouring sub-areas in total of $8 \mathrm{~km}^{2}$ (Orell \& Ojanen, 1983a, b; 133 Rytkönen \& Orell, 2001; Karvonen, Orell, Rytkönen, Broggi, \& Belda, 2012, Vatka et al., 2014, 134 Pakanen et al., 2016).

\section{$\underline{\text { Data collection }}$}

138 followed routine procedures (Orell \& Ojanen, 1983a, Orell \& Koivula, 1988, Orell, Lahti, Koivula, 139 Rytkönen, \& Welling, 1999). Nests were visited at least weekly and their contents were recorded. 140 The Willow Tit nests were checked through the entrance hole with the aid of a small mirror and a 141 torch, or through a small peak hole cut at the level of the nest, covered afterwards with birch bark. 142 The laying date of the first egg was as a rule calculated from the observed number of eggs in an 143 incomplete clutch (i.e., incubation had not yet started) under the assumption that one egg is laid per 144 day. The data consisted of 3331 and 3903 laying date records of first broods for the Willow Tit and 145 the Great Tit, respectively. 
Both the parents and young were marked with individually coded aluminium leg rings and parents with unique combinations of plastic colour rings, enabling pedigree construction and identification of individuals that recruited to the study populations. Birds were ringed under a license provided by the Finnish Natural History Museum, University of Helsinki. Parental birds were aged as yearlings or older either by calculating from the ringing date of recruits, or based on the tail feather shape in Willow Tits (Laaksonen \& Lehikoinen, 1976) or on plumage coloration in Great Tits (Svensson, 1992).

Pruned Willow Tit pedigree consisted of 1950 individuals and reached up to eight generations in depth. It contained the following pair-wise relatedness categories: $0.025(\mathrm{~N}=554), 0.05$ (460), 0.075 (3), 0.1 (1), 0.125 (638), 0.15 (4), 0.175 (4), 0.25 (793), 0.275 (2), 0.3 (5), 0.375 (1), 0.5 (907), $0.525(2), 0.55$ (1) and 0.625 (2). The relatedness category 0.5 signifies parent-offspring and full sib pairs, 0.25 grandparent-grandchild and half sib pairs, and 0.125 first cousins et cetera. Pruned Great Tit pedigree contained 3187 individuals, with a pedigree depth up to nine generations, with the following pair-wise relatedness categories: $0.025(\mathrm{~N}=85), 0.05(103), 0.125(196), 0.175(4), 0.25$

Data of daily mean ambient temperatures for 1969-2018 were retrieved from the Finnish

165 Random regression animal models were used to estimate how additive genetic variances and 166 heritabilities were related to spring temperatures. The function 'MCMCglmm' (library 'MCMCglmm'; Hadfield, 2010) was used to fit models in R 3.6.2 (R Core Team, 2019). Laying date $(y)$ of the individual $i$ in year $j$ was modelled as: 
170 where $\alpha_{y}$ is the intercept and $\beta_{1}$ and $\beta_{2}$ are regression coefficients for fixed effects female's age

$171\left(a g e_{i j}\right)$ and spring temperature $\left(T_{j}\right)$, respectively. Spring temperature was the mean temperature of periods 27 March-6 May or 29 March-15 May for the Willow and the Great Tits, respectively.

173 Spring temperature was mean centered. Year $\left(\right.$ year $\left._{j}\right)$ was used as a block random factor with 174 estimated variance of year $_{j} \sim N\left(0, \sigma_{y e a r}^{2}\right) . a_{i}$ and $b_{i}$ are female specific random intercepts and 175 slopes of permanent environmental effect, and $A_{i}$ and $B_{i}$ are random intercepts and slopes of the 176 additive genetic component. Permanent environmental and additive genetic variances were 177 estimated using two $2 \times 2$ variance-covariance matrices:

$P=\left[\begin{array}{cc}\sigma_{a}^{2} & \sigma_{a, b} \\ \sigma_{a, b} & \sigma_{b}^{2}\end{array}\right]$

$G=\left[\begin{array}{cc}\sigma_{A}^{2} & \sigma_{A, B} \\ \sigma_{A, B} & \sigma_{B}^{2}\end{array}\right]$

$e_{y, i j l}$ (eqn. 1) is the residual term. Possible heteroscedasticity of residual variance across spring temperatures was considered by estimating the residual variance for each equal-interval group $l$ of spring temperatures as $e_{y, i j l} \sim N\left(0, \sigma_{e, l}^{2}\right)$ (Ramakers et al. 2018a). The number of groups $n$ was 183 decided upon from four alternatives $(n=4,6,8$ or 10$)$ based on model comparison using DIC 184 values (Ramakers, Visser, \& Gienapp, 2020). For both species, $n=10$ was selected.

185 We used a wide normal distribution as a prior for fixed factors as a default. For the residual 186 variance, we used inverse-Wishart prior with $\mathrm{V}=\operatorname{diag}(n)$ and $\mathrm{nu}=0.002$. For other variance 187 components, parameter-expanded priors $(\mathrm{V}=\operatorname{diag}(x), \mathrm{nu}=x$, alpha.mu $=0$, alpha. $\mathrm{V}=$ 188 $\left.\operatorname{diag}(x)^{*} 1000\right)$ were used. A total of $10100000 \mathrm{MCMC}$ iterations were run for each species, 
including a burn-in period of 100000 iterations. The remaining 10000000 iterations were sampled with a thinning interval of 10000 , leading to sample sizes of 1000 saved iterations.

191 Additive genetic variances $\left(V_{A}\right)$ and heritabilities $\left(h^{2}\right)$ were estimated for each documented spring 192 temperature value for both species. The method described in the Appendix of Hadfield, Wilson, 193 Garant, Sheldon, and Kruuk (2010) was applied to create confidence intervals for these estimates.

194 This involved calculation of the above-mentioned estimates for each of the saved 1000 iterations to 195 create distributions of estimated values, of which median values are reported along with 95\% HPD 196 intervals using function 'HPDinterval' in library 'coda' (Plummer, Best, Cowles, \& Vines 2006).

$197 \mathrm{~V}_{\mathrm{A}}$ for each spring temperature value $T_{j}$ were derived using the $\mathbf{G}$ matrix as

$V_{A_{j}}=\sigma_{A}^{2}+2 \sigma_{A, B} T_{j}+\sigma_{B}^{2} T_{j}^{2}$

199 and $\mathrm{V}_{\mathrm{PE}}$ similarly using the $\mathbf{P}$ matrix. Temperature-dependent heritability was calculated as

$h_{j}^{2}=\frac{V_{A_{j}}}{V_{A_{j}}+V_{P E_{j}}+\sigma_{y e a r}^{2}+\sigma_{e, l}^{2}}$,

where $\sigma_{e, l}^{2}$ is the error variance component in the corresponding temperature group $l$. Temperaturedependent $V_{A}$ and $h^{2}$ values were plotted against spring temperatures.

$\underline{\text { Selection on the breeding time }}$

We studied which temperature periods (viz. spring, autumn and winter) affect selection on breeding time. These periods were selected a priori to present different potential mechanisms of selection. Spring temperatures (the mean temperature of periods March 27-May 6 or 29 March-15 May for the Willow and the Great Tit, respectively) may affect the temporal match-mismatch with food availability during the nestling period (Vatka et al., 2011), which in turn may affect breeding success and thus selection on the timing of breeding. Temperatures of the following autumn (the

211 mean temperature of August-October) coincide with the period of intensive food hoarding in the 
212 Willow Tit (Haftorn, 1956), and winter temperatures (the mean temperature of December-

213 February) represent the coldest time of the year. These may affect survival, and thus, recruitment

214 rates of the young.

215 We used generalized linear mixed effect models fit with function 'glmer' in library 'Ime4' (Bates,

216 Mächler, Bolker, \& Walker, 2015) with Poisson error structure. In these models, the response

217 variable was annual proxy of individual fitness, measured as the number of recruits a female

218 produced annually, including recruits from the first brood and a potential re-nesting attempt or

219 second brood. The number of recruits (rather than the number of fledglings or eggs produced) was

220 used as a proxy of fitness, because the definition of fitness refers to the relative contribution of a

221 phenotype to the future generations (e.g. Krebs, 2009) and thus, only offspring that make it to

222 express the trait (the timing of breeding) count. However, for comparison we present an analysis

223 with the number of fledglings as a proxy of individual fitness in Appendix 1. Annual proxy of

224 individual fitness was regressed against the annually centered timing of breeding of the female's

225 first brood in interaction with temperature (centered temperatures of the three periods were tested

226 one at a time). A significant interaction term would tell that ambient temperatures affect selection

227 on the timing of breeding. Female identity and year were used as block random factors.

228 These analyses were restricted to years 1991-2017 and 1999-2017 for the Willow and the Great

229 Tit, respectively. These restrictions were applied because the Willow Tit study area was small and

230 fragmented before 1991 (Lampila, Orell, Belda, \& Koivula, 2006), and the Great Tit study area

231 reached its current extent in 1998. Thus, early years were omitted in order to acquire selection

232 gradients that are comparable between years. In 1998, a large number of Great Tit nests were

233 experimentally destroyed during the incubation stage, and therefore this year was also excluded

234 from the analysis. 
236 Covariance of measures of evolutionary potential and selection

237 To estimate annual selection gradients, we used models with Poisson error structure fit by

238 'MCMCglmm'. Annual proxy of individual fitness (measured as the number of recruits a female

239 produced annually) was regressed against the standardized timing of breeding (centered to a mean

240 of zero and scaled to a variance of one) in annual subsets of data. Standardisation was done before

241 creating annual subsets. Regression coefficients $\beta_{j}$ were interpreted as directional selection

242 gradients (Morrissey \& Goudie, 2016).

243 We examined covariance of different measures of evolutionary potential (i.e., expressed additive 244 genetic variation and heritability) and selection. As explained above, $V_{A_{j}}$ and $h_{j}^{2}$ were calculated 245 and $\beta_{j}$ were retrieved for each of the 1000 saved iterations. We calculated Pearson's correlation 246 coefficients $r$ between each $k^{\text {th }}$ set of values of $V_{A_{j}}$ or $h_{j}^{2}$ and $\beta_{j}$, reporting their mean and HPD 247 intervals. In similar fashion, we calculated Pearson's correlation coefficients $r$ between measures of 248 evolutionary potential and $\left|\beta_{j}\right|$ to infer the covariance between evolutionary potential and the 249 strength of selection (regardless of its direction). 


\section{Results}

Effects of spring temperatures on additive genetic variance and heritability

254 The amount of additive genetic variance $\left(V_{A}\right)$ expressed in laying date tended to be higher for Great

255 Tits than for Willow Tits (Fig. 1a, b), but in both species $V_{A}$ was independent of spring temperatures 256 (Fig. 1a, b). In fact, the variance attributable to random slopes of the additive genetic component $\sigma_{B}^{2}$ 257 was low in both species (Table S1, Table S2).

258 Heritability estimates $\left(h^{2}\right)$ of laying date were somewhat low both in the Willow Tit $\left(h^{2}\right.$ range $=$ 259 0.134-0.238; Table S3) and the Great Tit $\left(h^{2}\right.$ range $=0.237-0.425$; Table S4), and independent of 260 spring temperatures (Fig. 1c, d). There was some variability in heritability estimates especially in 261 the Great Tit (Fig. 1d), owing to variation in estimated error variances between different 262 temperature groups (Table S2).

264 Effects of ambient temperatures on the strength of selection

265 Early broods produced more recruits than late broods and thus, there was a significant selection 266 pressure for earlier breeding in the Willow Tit (Table 1). However, for the Great Tit, the main effect 267 of the timing of breeding on recruitment rate was nonsignificant and thus no significant overall 268 selection for earlier breeding was found (Table 2). The strength of directional selection on the 269 timing of breeding was independent of spring temperatures in both species (Table 1, Table 2). In the 270 Willow Tit, selection for earlier breeding was more intense when the temperatures of the following 271 autumn or winter were cold, indicated by significant interaction terms Timing*Temperature (Table 272 1). Winter temperatures had also a significantly negative main effect, meaning that recruitment rates 273 are lower in warm winters (Table 1). In the Great Tit, autumn or winter temperatures did not affect 274 the strength of directional selection on reproductive timing (Table 2). 
276 Covariance of measures of evolutionary potential and selection

277 There was year-to-year variation in the selection gradients $\beta$ on breeding time, ranging from -1.208

278 to 0.246 in the Willow Tit $(\bar{\beta}=-0.408)$ and from -0.634 to 1.497 in the Great Tit $(\bar{\beta}=0.006$; Table

279 S5). Neither the levels of expressed additive genetic variance nor heritability were correlated with 280 annual selection gradients, or with the strength of selection in either species (Table 3). 


\section{Discussion}

282 We did not detect any significant changes in the expression of additive genetic variance or 283 heritability with warming spring temperatures. As in the case of our results, $V_{A}$ in timing of 284 breeding did not change with warming springs in a UK Great Tit population (Husby et al., 2010). 285 Similarly, Ramakers, Gienapp, and Visser (2018) found little genotype-by-environment interaction 286 in the timing of breeding related to spring temperatures in a Dutch Great Tit population. However, 287 inconsistent effects of environmental conditions on expression of additive genetic variance have 288 been reported in other traits (Hoffmann \& Merilä, 1999).

Heritability values of breeding time were rather low, which is typical of avian life-history traits (e.g. Merilä \& Sheldon, 2000, McCleery et al., 2004). The observed variation in heritability estimates was mostly due to variation in residual variance estimates between different temperature groups, rather than due to variation in the additive genetic variance component. Studies from other Great Tit populations have reported heritability values on breeding time that are somewhat lower than the values we report here ( $h^{2}$ range: $0.237-0.425$; an overall average $=0.332$, Table S4). McCleery et al. (2004) reported a heritability of $0.159(\mathrm{SE}=0.059)$ for Wytham Woods population, whereas 296 Gienapp, Calus, Laine, and Visser (2019) estimated heritability of 0.24 ( $\mathrm{SE}=0.07)$ based on a social pedigree and $0.17(\mathrm{SE}=0.06)$ based on kinships inferred from genetic markers for Hoge Veluwe population. To our knowledge, no other heritability estimates of the timing of breeding are available for the Willow Tit. That the additive genetic variance and heritability were lower in the Willow than 300 in the Great Tit makes sense in the light that the timing of breeding in Willow Tits seem to be a 301 subject for directional selection more often than in Great Tits, and because directional selection is expected to erode genetic variation. Whatever the ultimate reason for the low heritability, low heritabilites translate to low rates of expected evolutionary change for given intensity of selection (Falconer \& Mackay, 1996). As the heritabilities in both species did not show any trend in relation 
to spring temperatures, warming of springs are not expected to neither accelerate nor slow down evolutionary responses as far as the effect of heritability values is concerned.

As noted also in earlier studies (e.g. Sheldon, Kruuk, \& Merilä, 2003, Husby, Visser, \& Kruuk, 2011, Visser et al., 2015), the strength of directional selection on breeding time was quite variable among years. However, in spite of the fact that boreal Willow and Great Tits show advancing longterm trends in their timing of breeding (Vatka et al., 2011, 2014), we did not detect statistically significant directional selection for earlier breeding in the Oulu Great Tit population. This indicates that the observed change in the timing of breeding in the Great Tit results most likely from phenotypic plasticity, and hence, is not a genetically based evolutionary response (cf. Charmantier, \& Gienapp, 2014). In contrast, we found significant selection for earlier breeding in the Willow Tit, which in combination with low but significant heritability of breeding time should promote evolutionary response towards earlier breeding. However, to what degree the advanced breeding time in the Willow Tit reflects genetic vs. plastic changes remains to be investigated.

Spring temperatures do not seem to influence selection on the timing of breeding in either of the two study species. Yet, spring temperatures affect the synchrony between the breeding time and the timing of caterpillar food availability in the Willow Tit: synchrony is better in warm years (Vatka et al., 2011). In contrast, Great Tits advance their breeding time at the same rate as the timing of the caterpillar food peak advances with rising spring temperatures, and thus, spring temperatures do not affect the level of synchrony in the Oulu Great Tit population (Vatka et al., 2014). Hence, one would expect that spring temperatures would influence selection on the timing of breeding in the Willow Tit. However, a previous study suggests that the synchrony with the caterpillar food peak is not the most relevant selection mechanism in the Willow Tit - instead, timing of breeding in relation to conspecifics affected recruitment rate (Pakanen et al., 2016). Visser et al. (2015) also

328 found a similar lack of association between the level of synchrony with the food availability and 329 selection on the timing of breeding in migratory Pied Flycatchers (Ficedula hypoleuca). 
Autumn and winter temperatures were found to affect the strength of selection on the timing of

331 breeding in the Willow Tit. This is an understandable outcome when considering the species'

332 ecology. Willow Tits spend their winters in flocks whose social hierarchy is affected by prior

333 residency (Koivula et al., 1993). They hoard food in autumn (Brodin et al., 1996) and young from

334 early broods have more time to prepare for the winter. Thus, young from early broods are in a better

335 position to survive than young from late broods. This seems to be particularly so when autumns and

336 winters are cold. Autumn temperatures likely affect food hoarding, inducing a selection pressure on

337 breeding time. Cold winters are associated with higher overall recruitment rate, but selection for

338 earlier breeding is more intense when winters are cold. Rapid warming of autumns and winters

339 appear to reduce the strength of directional selection for earlier breeding. This in turn can reduce the

340 rate of expected evolutionary change, unless some other important ultimate factor(s) comes into

341 play.

342 That warm winters are associated with lower recruit production in the Willow Tit can be explained

343 by several mechanisms, yet they are so far only speculative explanations. Temperatures fluctuating

344 above and below the freezing point can first melt the snow and then create an ice shield covering

345 the food hoards. Warm winters can cause food hoards to decay (Sechley, Strickland, \& Norris,

346 2015), and thus food availability can decrease drastically. It is also possible that wet weathers (rain

347 coming down as water instead of snow) affect the thermoregulation of birds when plumage gets

348 wet. Winter rain can decrease foraging efficiency during short days, followed by cold and long

349 nights. These mechanisms would likely affect all birds similarly, regardless of their social status or

350 birth date.

351 In order to understand how environmental changes affect natural selection, one needs to identify the

352 life stage when selection kicks in. In the boreal zone, (pre-)winter conditions seem to play an

353 important role for the selection on breeding time. The situation may be different in temperate zone

354 populations where winters are not equally harsh. Visser et al. (2015) found that in a long-distance 
migratory bird, temperatures at the time of arrival to the breeding grounds affected selection on timing of reproduction. They suggested that environmental conditions with a lag of up to two years can affect selection on a phenological trait (Visser et al., 2015). We also found that environmental conditions affect selection on timing of breeding with a temporal lag, although in our case the lag was not more than about six months. It is important to recognize that evolution of the timing of breeding, a life history event that takes place in spring, can be regulated by environmental

361 conditions outside this period. In other words, one needs to consider the whole lifespan of individuals when trying to assess factors influencing a certain life-history trait.

(Ramakers et al., 2018, but see Merilä, 1997, Wilson et al., 2006, Husby et al., 2011). In accordance with this, we did not find any strong correlations between the different measures of evolutionary potential and the selection or its strength. This corresponds with the finding of little changes in evolutionary potential with the environment. In this perspective, it might be worth emphasizing that it may be relevant to consider separately on the one hand factors that affect the expressed amount of heritable variation, and on the other hand factors that affect selection on the trait in question - these might be totally distinct factors, influenced differently by changes in environmental conditions. If this is a common, or a general pattern, it will be difficult to predict how populations respond to selection brought by, for instance, changing climatic conditions.

\section{$\underline{\text { Conclusions }}$}

375 The results suggest that climate warming will neither constrain nor promote evolutionary potential 376 in boreal populations of Willow and Great Tits. However, environmental conditions can affect 377 selection on breeding time with a temporal lag: evolution of a life history event that takes place in 378 springtime appears to be regulated by conditions prevailing in following autumns and winters in the 
379 Willow Tit. Hence, in the light of the findings of this study, rapid warming of these periods can be 380 expected to reduce the strength of directional selection for earlier breeding, and thereby also the 381 expected evolutionary response to selection. 


\section{Acknowledgements}

383 We acknowledge all the people who have participated in collecting the parid breeding data, 384 especially M Ojanen, K Koivula, K Lahti, K Kumpulainen, P Welling, M Leppäjärvi, N Verboven, 385 J Broggi, E Belda, S Lampila, J Karvonen, C Westerduin, J Ollinmäki, J Laukkala, numerous 386 graduate students and staff of the Biodiversity Unit, University of Oulu. We thank Finnish 387 Meteorological Institute for providing the data of ambient temperatures and M Morrissey, P 388 Gienapp and M Kivikoski for valuable discussions. EV was funded by the Ella and Georg 389 Ehrnrooth Foundation. Academy of Finland and Kvantum Institute, University of Oulu provided 390 funding for data collection. Authors have no conflicts of interests.

\section{Authors' contributions}

$\mathrm{EV}, \mathrm{JM}$ and MO conceived the ideas; MO, SR and EV collected the data; EV analysed the data and

394 led the writing of the manuscript. All authors contributed critically to the drafts and gave final 395 approval for publication.

\section{Data Availability Statement}

399 et al., 2020). 


\section{References}

Bates, D., Mächler, M., Bolker, B. M., \& Walker, S. C. (2015). Fitting linear mixed-effect models using lme4. Journal of Statistical Software, 67, 1-48. doi: 10.18637/jss.v067.i01

Brodin, A., Lahti, K., Lens, L., \& Suhonen, J. (1996). A northern population of willow tits Parus montanus did not store more food than southern ones. Ornis Fennica, 73, 114-8.

Charmantier, A., \& Gienapp, P. (2014). Climate change and timing of avian breeding and migration: evolutionary versus plastic changes. Evolutionary Applications, 7, 15-28. doi: 10.1111/eva.12126

Falconer, D. S., \& Mackay, T. F. C. (1996). Introduction to Quantitative Genetics. Longman Group Limited, Essex.

Gebhardt-Henrich, S. G., \& van Noordwijk, A. J. (1991). Nestling growth in the Great Tit I. Heritability estimates under different environmental conditions. Journal of Evolutionary Biology, 3, 341-362. doi: 10.1046/j.1420-9101.1991.4030341.x

Gienapp, P., Calus, M. P. L., Laine, V. N., \& Visser, M. E. (2019). Genomic selection on breeding time in a wild bird population. Evolution Letters, 3, 142-151. doi: 10.1002/ev13.103

Hadfield, J. (2010). MCMC methods for multi-response generalized linear mixed models: the MCMCglmm R package. Journal of Statistical Software, 33, 1-22. doi: 10.18637/jss.v033.i02

Hadfield, J. D., Wilson, A. J., Garant, D., Sheldon, B. C., \& Kruuk, L. E. B. (2010). The misuse of BLUP in ecology and evolution. The American Naturalist, 175, 116-125. doi: $10.1086 / 648604$ 
Haftorn, S. (1956). Contribution to the food biology of tits especially about storing of surplus food Part III The Willow Tit (Parus atricapillus L.). Det Kgl Norske Videnskabers Selskabs Skrifter 1956 Nr 3, 1-79.

Hansen, T. F., Pélabon, C., \& Houle, D. (2011). Heritability is not evolvability. Evolutionary Biology, 38, 258-277. doi: 10.1007/s11692-011-9127-6

Hoffmann, A. A., \& Merilä, J. (1999). Heritable variation and evolution under favourable and unfavourable conditions. Trends in Ecology \& Evolution, 14, 96-101. doi: 10.1016/S01695347(99)01595-5

Houle, D. (1992). Comparing evolvability and variability of quantitative traits. Genetics, 130, 195204.

Husby, A., Nussey, D. H., Visser, M. E., Wilson, A. J., Sheldon, B. C., \& Kruuk, L. E. B. (2010). Contrasting patterns of phenotypic plasticity in reproductive traits in two great tit (Parus major) populations. Evolution, 64, 2221-2237. doi: 10.1111/j.1558-5646.2010.00991.x

Husby, A., Visser, M. E., \& Kruuk, L. E. B. (2011). Speeding up microevolution: the effects of increasing temperature on selection and genetic variance in a wild bird population. PLoS Biology, 9, e1000585. doi: 10.1371/journal.pbio.1000585

Hyvärinen, E., Juslén, A., Kemppainen, E., Uddström, A. \& Liukko, U.-M. (eds.) (2019). The 2019 Red List of Finnish Species. Ympäristöministeriö \& Suomen ympäristökeskus. Helsinki. 704 p.

Karvonen, J., Orell, M., Rytkönen, S., Broggi, J. \& Belda, E. (2012). Population dynamics of an expanding passerine at the distribution margin. Journal of Avian Biology, 43, 102-108. doi: 10.1111/j.1600-048X.2011.05376.x 
443 Koivula, K., Lahti, K., Orell, M., \& Rytkönen, S. (1993). Prior residency as a key determinant of 444 social dominance in the willow tit (Parus montanus). Behavioral Ecology and Sociobiology, 33, 283-287. doi: 10.1007/BF02027126

Krebs, C. J. (2009). Ecology. The Experimental Analysis of Distribution and Abundance. $6^{\text {th }}$ ed. Pearson.

Laaksonen, M., \& Lehikoinen, E. (1976). Age determination of willow and crested tit Parus montanus and P. cristatus. Ornis Fennica, 53, 9-14.

Lampila, S., Orell, M., Belda, E., \& Koivula, K. (2006). Importance of adult survival, local recruitment and immigration in a declining boreal forest passerine, the willow tit Parus montanus. Oecologia, 148, 405-413. doi: 10.1007/s00442-006-0386-3

Lynch, M., \& Walsh, B. (1998). Genetics and Analysis of Quantitative Traits. Sinauer, Sunderland, MA.

McCleery, R. H., Pettifor, R. A., Armbruster, P., Meyer, K., Sheldon, B. C., \& Perrins, C. M. (2004). Components of variance underlying fitness in a natural population of the great tit Parus major. The American Naturalist, 164, E62-E72. doi: 10.1086/422660

Morrissey, M. B., \& Goudie, I. G. J. (2016). Analytical results for directional and quadratic selection gradients for log-linear models of fitness functions. biorxiv.org preprint. doi: $10.1101 / 040618$

Orell, M., \& Koivula, K. (1988). Cost of reproduction: parental survival and production of recruits in the Willow Tit Parus montanus. Oecologia, 77, 423-432. doi: 10.1007/BF00378054.

Orell, M., \& Ojanen, M. (1983a). Timing and length of the breeding season of the great tit Parus major and the willow tit P. montanus near Oulu, Northern Finland. Ardea, 71, 183-198. 
Orell, M., \& Ojanen, M. (1983b). Effect of habitat, date of laying and density on clutch size of the Great Tit Parus major in northern Finland. Holarctic Ecology, 6, 413-423.

Orell, M., \& Ojanen, M. (1983c). Breeding biology and population dynamics of the willow tit Parus montanus. Annales Zoologici Fennici, 20, 99-114.

Orell, M. (1989). Population fluctuations and survival of Great Tits Parus major dependent on food supplied by man in winter. Ibis, 131, 112-127. doi: 10.1111/j.1474-919X.1989.tb02750.x

Orell, M., Lahti, K., Koivula, K., Rytkönen, S., \& Welling, P. (1999). Immigration and gene flow in a northern willow tit (Parus montanus) population. Journal of Evolutionary Biology, 12, 283295. doi: 10.1046/j.1420-9101.1999.00030.x

Pakanen, V.-M., Orell, M., Vatka, E., Rytkönen, S., \& Broggi, J. (2016). Different ultimate factors define timing of breeding in two related species. PLoS ONE, 11(9), e0162643. doi: 10.1371/journal.pone.0162643

Parmesan, C., \& Yohe, G. (2003). A globally coherent fingerprint of climate change impacts across natural systems. Nature, 421, 37-42. doi: 10.1038/nature01286

Pigliucci, M. (2001). Phenotypic Plasticity: Beyond Nature and Nurture. Baltimore, U.S.A: John Hopkins University Press.

Plummer, M., Best, N., Cowles, K., \& Vines, K. (2006) CODA: Convergence Diagnosis and Output Analysis for MCMC. R News, 6, 7-11.

R Core Team (2019). R: A language and environment for statistical computing. R Foundation for Statistical Computing, Vienna, Austria. URL https://www.R-project.org/.

Ramakers, J. J. C., Culina, A., Visser, M. E., \& Gienapp, P. (2018a). Environmental coupling of heritability and selection is rare and of minor evolutionary significance in wild populations. Nature Ecology \& Evolution, 2, 1093-1103. doi: 10.1038/s41559-018-0577-4 
Ramakers, J. J. C., Gienapp, P., \& Visser, M. E. (2018b). Phenological mismatch drives selection on elevation, but not on slope, of breeding time plasticity in a wild songbird. Evolution, 73, 175-187. doi: 10.1111/evo.13660

Ramakers, J. J. C., Visser, M. E., \& Gienapp, P. (2020). Quantifying individual variation in reaction norms: Mind the residual. Journal of Evolutionary Biology, 33, 352-365. doi: 10.1111/jeb.13571

Root, T. L., Price, J. T., Hall, K. R., Schneider, S. H., Rosenzweig C., \& Pounds, J. A. (2003). Fingerprints of global warming on wild animals and plants. Nature, 421, 57-60. doi: 10.1038/nature01333

Ruosteenoja, K., Jylhä, K., \& Kämäräinen, M. (2016). Climate projections for Finland under the RCP forcing scenarios. Geophysica, 51, 17-50.

Rytkönen, S., \& Orell, M. (2001). Great tits (Parus major) lay too many eggs: experimental evidence in mid-boreal habitats. Oikos, 93, 439-450. doi: 10.1034/j.16000706.2001.930309.x

Sechley, T. H., Strickland, D., \& Norris, D. R. (2015). Linking the availability of cached food to climate change: an experimental test of the hoard-rot hypothesis. Canadian Journal of Zoology, 93, 411-419. doi: 10.1139/cjz-2015-0016

Sheldon, B. C., Kruuk, L. E. B., \& Merilä, J. (2003). Natural selection and inheritance of breeding time and clutch size in the collared flycatcher. Evolution, 57, 406-420. doi: 10.1111/j.00143820.2003.tb00274.x

Svensson, L. (1992). Identification guide to European passerines, $4^{\text {th }}$ edn. British Trust for Ornithology. 
Valkama, J., Vepsäläinen, V., \& Lehikoinen, A. (2011). The Third Finnish Breeding Bird Atlas. Finnish Museum of Natural History and Ministry of Environment. <http://atlas3.lintuatlas.fi/english> (cited 11.3.2019) ISBN 978-952-10-7145-4

Vatka, E., Orell, M., \& Rytkönen, S. (2011). Warming climate advances breeding and improves synchrony of food demand and food availability in a boreal passerine. Global Change Biology, 17, 3002-3009. doi: 10.1111/j.1365-2486.2011.02430.x

Vatka, E., Orell, M., Rytkönen, S., \& Merilä, J. (2020) Data from: Effects of ambient temperatures on evolutionary potential of reproductive timing in boreal passerines. Dryad Digital Repository, https://doi.org/10.5061/dryad.s1rn8pk5w

Vatka, E., Rytkönen, S., \& Orell, M. (2014). Does the temporal mismatch hypothesis match in boreal populations? Oecologia, 176, 595-605. doi: 10.1007/s00442-014-3022-7

Visser, M. E., \& Both, C. (2005). Shifts in phenology due to global climate change: the need for a yardstick. Proceedings of the Royal Society B, 272, 2561-2569. doi: 10.1098/rspb.2005.3356

Visser, M. E., Gienapp, P., Husby, A., Morrisey, M., de la Hera, I., Pulido, F., \& Both, C. (2015). Effects of spring temperatures on the strength of selection on timing of reproduction in a longdistance migratory bird. PLoS Biology, 13, e1002120. doi: 10.1371/journal.pbio.1002120

Wilson, A. J., Pemberton, J. M., Pilkington, J. G., Coltman, D. W., Mifsud, D. V., Clutton-Brock, T. H., \& Kruuk, L. E. B. (2006). Environmental coupling of selection and heritability limits evolution. PLoS Biology, 4, e216. doi: 10.1371/journal.pbio.0040216 


\section{$529 \quad$ Figure legends}

530

531 Figure 1. Additive genetic variances (A-B) and heritabilities (C-D) of breeding time in relation to 532 spring temperatures in the Willow Tit $(\mathrm{A}, \mathrm{C})$ and the Great Tit $(\mathrm{B}, \mathrm{D})$.

533 
536 Table 1. Parameters of generalized linear mixed effect models explaining annual proxy of

537 individual fitness (measured as the number of recruits produced) in the Willow Tit. Explanatory

538 variables are centered. A significant interaction term (Timing*Temperature) indicates that selection

539 on the timing of breeding is influenced by ambient temperatures. Statistically significant $(\mathrm{p}<0.050)$

540 parameter estimates are depicted in boldface.

\begin{tabular}{|c|c|c|c|c|c|c|}
\hline \multicolumn{2}{|c|}{ Model } & Fixed effects & Estimate & $\mathrm{SE}$ & $\mathrm{Z}$ value & $\mathrm{p}$ \\
\hline \multirow{4}{*}{ 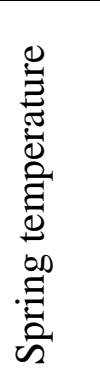 } & & Intercept & -1.534 & 0.112 & -13.686 & $<0.001$ \\
\hline & & Timing of breeding & -0.067 & 0.010 & -6.510 & $<0.001$ \\
\hline & & Temperature & -0.042 & 0.079 & -0.534 & 0.594 \\
\hline & & Timing*Temperature & 0.003 & 0.007 & 0.470 & 0.638 \\
\hline \multirow{4}{*}{ 当 } & \multirow{4}{*}{ 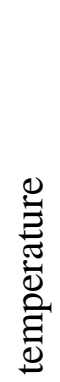 } & Intercept & -1.544 & 0.113 & -13.657 & $<0.001$ \\
\hline & & Timing of breeding & -0.071 & 0.010 & -6.861 & $<0.001$ \\
\hline & & Temperature & -0.040 & 0.108 & -0.373 & 0.709 \\
\hline & & Timing*Temperature & 0.026 & 0.012 & 2.159 & 0.031 \\
\hline \multirow{4}{*}{ 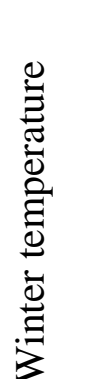 } & & Intercept & -1.550 & 0.102 & -15.130 & $<0.001$ \\
\hline & & Timing of breeding & -0.066 & 0.010 & -6.434 & $<0.001$ \\
\hline & & Temperature & -0.086 & 0.036 & -2.351 & 0.019 \\
\hline & & Timing*Temperature & 0.009 & 0.004 & 2.169 & 0.030 \\
\hline
\end{tabular}


543 Table 2. Parameters of generalized linear mixed effect models explaining annual proxy of

544 individual fitness (measured as the number of recruits produced) in the Great Tit. Explanatory

545 variables are centered. A significant interaction term (Timing*Temperature) would indicate that

546 selection on the timing of breeding is influenced by ambient temperatures. Statistically significant

$547 \quad(\mathrm{p}<0.050)$ parameter estimates are depicted in boldface.

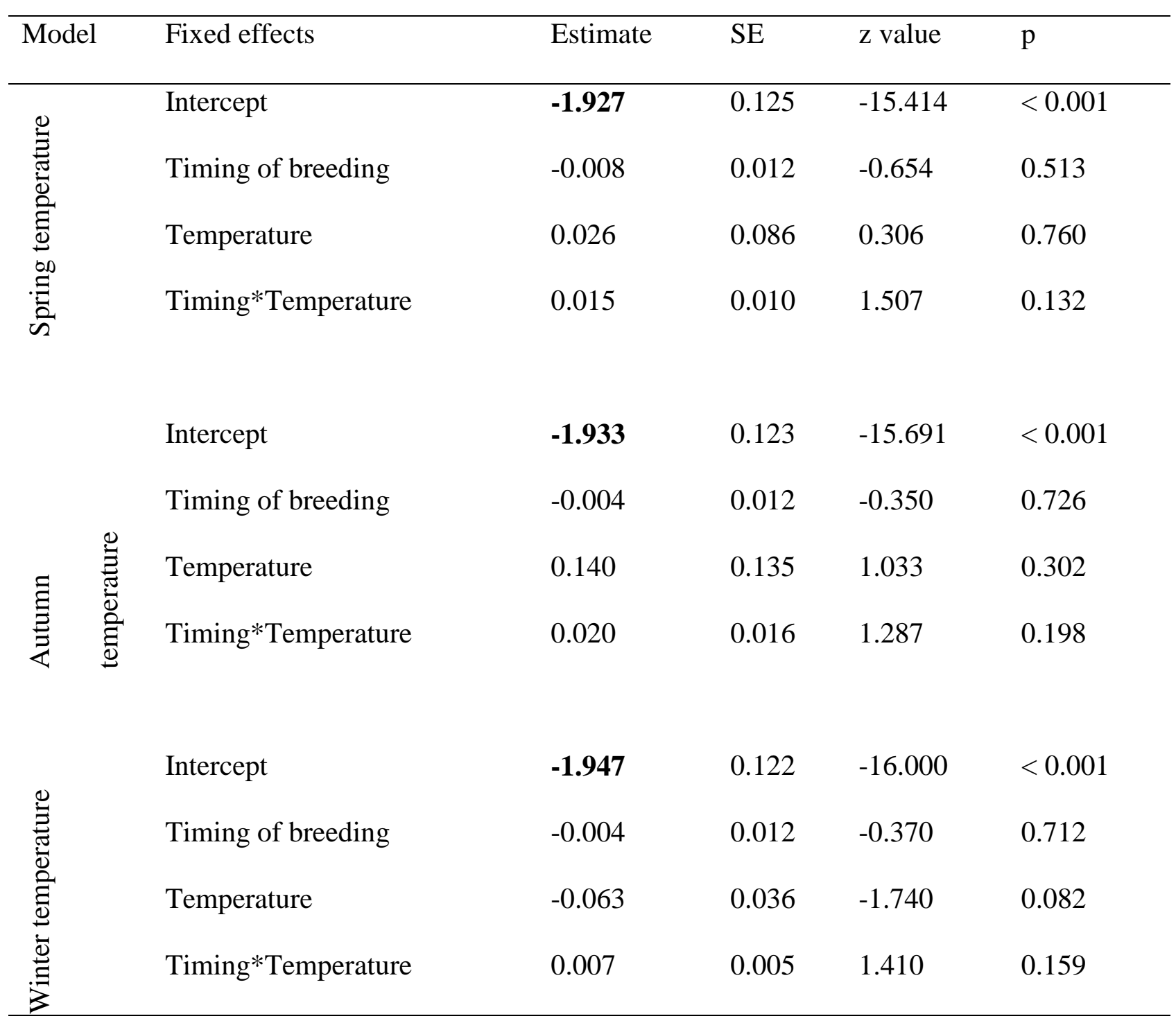


551 Table 3. Pearson's correlation coefficients $r$ (and their 95\% HPD intervals) between different

552 measures of evolutionary potential and selection in the Willow Tit and the Great Tit.

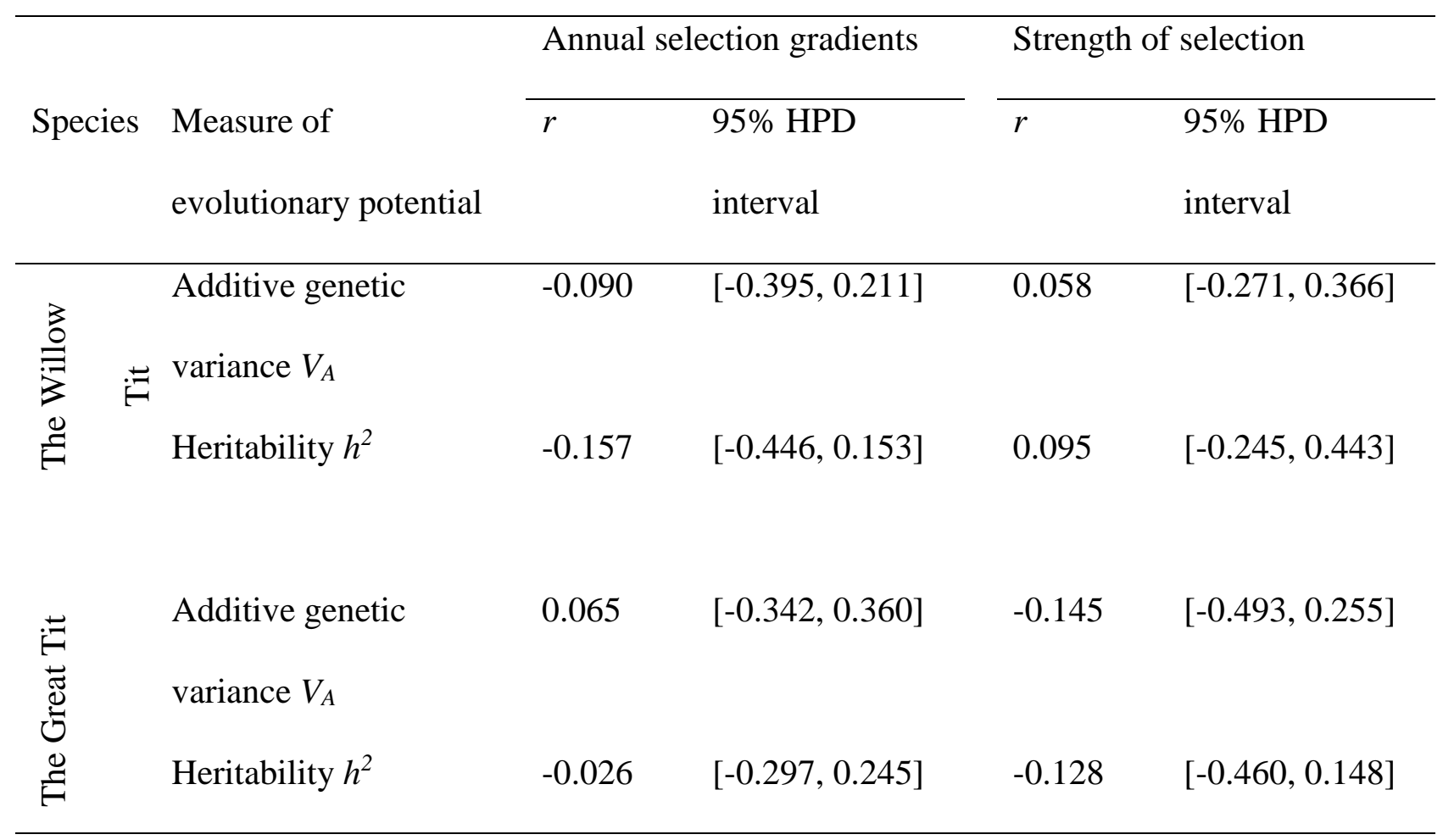

